20. SWAMP: An IoT-based Smart Water Management Platform for Precision Irrigation in Agriculture / C. Kamienski [et al.] // Proceedings of the IEEE Global IoT Summit 2018 (GI-oTS'18), Bilbao, Spain, 4-7 June 2018. https://www. ncbi.nlm. nih. gov/pubmed/30641960.

21. Tevatronic. Autonomous Irrigation. http://tevatronic.net.

22. Variable Rate Irrigation (VRI) Animation. www.youtube.com/watch? $=\mathrm{v}=\mathrm{tDfSqAz} 11 \mathrm{~s}$.

23. Yang S. H. Internet-based Control Systems: Design and Applications. Springer, 2011. 224 p.

\title{
Информация об авторе
}

Юрченко Ирина Федоровна, главный научный сотрудник отдела «Природоохранных и информационных технологий» Всероссийского научно иследовательского института гидротехники и мелиорации имени А. Н. Костякова (РФ, 127550 г. Москва, ул. Большая Академическая , дом 44, строение 2), доктор технических наук, доцент, ORCID: 0000-0003-2390-1736. Тел. +7 916 328-85-1, e-mail: Irina.507@mail.ru

\section{Author's information}

Irina Yurchenko, chief researcher of the Department of Environmental and information technologies of the all-Russian research Institute of hydraulic engineering and land reclamation named after A. N. Kostyakov (Russia, 127550 Moscow, Bolshaya Akademicheskaya str., building 2), doctor of technical Sciences, associate Professor, ORCID: 0000-0003-2390-1736. Tel.+7 916 328-85-1, e-mail: Irina.507@mail.ru \section{METHOD FOR PROTECTING SLOPES FROM WATER EROSION}

DOI: 10.32786/2071-9485-2021-03-40

\author{
A. V. Slabunova, V. V. Slabunov \\ Federal State Budget Scientific Institution \\ «Russian Research Institute for Melioration Problems», Novocherkassk \\ Received 28.04.2021 \\ Submitted 23.08.2021
}

\begin{abstract}
Introduction. The Rostov region is a region of wide and widespread water erosion, and therefore agriculture in the region under consideration should have a pronounced soil protection character. Currently, various technologies and solutions are used to protect the soil from erosion, but they require constant improvement, which, in turn, makes it necessary to develop new methods and methods obtained on the basis of ongoing scientific research, both in Russia and abroad, as well as more affordable in financial terms to agricultural producers. The purpose of the study is to develop improved design solutions for anti-erosion hydraulic structures to protect slopes from water erosion. An object. The object of research is antierosion hydraulic structures. Materials and methods. The information base of the research was made up of: studies of various authors devoted to the problem of water erosion, materials of patent search for known design solutions that contribute to the protection of slopes from water erosion. Comparative analysis of design solutions was carried out using general scientific (analysis and synthesis) methods. Results and conclusions. A constructive solution of an anti-erosion hydraulic structure is proposed, including the creation of a water-distributing trench oriented along the horizontal terrain, with a water-retaining earthen shaft and a water-retaining screen, the trench is filled with filler. In this case, the water-retaining screen is made by covering the wall of the trench adjacent to the water-retaining earthen shaft with a geocomposite drainage material with a geomembrane, together with the shaft, and the opposite wall and the bottom of the trench are covered with a geocomposite drainage material. As a filler, a water-conducting natural filler in the form of expanded clay gravel with a fraction of $20-40 \mathrm{~mm}$ is used. Thanks to the proposed design solution, the reliability and stability of the operation of the anti-erosion structure increases and, as a result, the effectiveness of combating water erosion on arable slope lands increases.
\end{abstract}

Key words: water erosion, anti-erosion hydraulic structures, erosion processes, method of protecting slopes from water erosion, surface runoff.

Citation. Slabunova A. V., Slabunov V. V. Method for protecting slopes from water erosion. Proc. of the Lower Volga Agro-University Comp. 2021. 3(63). 388-396 (in Russian). DOI: 10.32786/20719485-2021-03-40. 


\title{
***** HЗBECTHЯ ***** \\ НИЖНЕВОАЖСКОГО АГРОУНИВЕРСИТЕТСКОГО КОМПАЕКСА: НАУКА И ВЫСШЕЕ ПРОФЕССИОНААЬНОЕ ОБРАЗОВАНИЕ
}

Author's contribution. All authors of this research paper have directly participated in the planning, execution, or analysis of this study. All authors of this paper have read and approved the final version submitted.

Conflict of interest. The authors declare no conflict of interest.

УДК 631.6.001.4

\section{СПОСОБ ЗАЩИТЫ СКЛОНОВ ОТ ВОДНОЙ ЭРОЗИИ}

\author{
А. В. Слабунова, кандидат технических наук \\ В. В. Слабунов, кандидат технических наук \\ ФГБНУ Российский научно-исследовательский институт проблем мелиорачии, \\ 2. Новочеркасск
}

Дата поступления в редакцию 28.04.2021

Дата принятия к печати 23.08.2021

Актуальность. Ростовская область - регион широкого и повсеместного распространения водной эрозии, в этой связи земледелие в рассматриваемом регионе должно носить ярко выраженный почвозащитный характер. В настоящее время для защиты почвы от эрозии используются различные технологии и пути решения проблемы, однако они требуют постоянного совершенствования, что, в свою очередь, вызывает необходимость разработки новых способов и методов, полученных на основании непрекращающихся научных исследований, как в России, так и за рубежом, а также более доступных в финансовом плане для сельхозтоваропроизводителей. Цель исследования - разработка усовершенствованных конструктивных решений противоэрозионных гидротехнических сооружений для защиты склонов от водной эрозии. Объект. Объектом исследований являются противоэрозионные гидротехнические сооружения. Материалы и методы. Информационную основу исследования составили исследования различных авторов, посвященные проблеме водной эрозии, материалы патентного поиска известных конструктивных решений, способствующих защите склонов от водной эрозии. Сравнительный анализ конструктивных решений проводился с помощью общенаучных (анализ и синтез) методов. Результаты и выводы. Предложено конструктивное решение противоэрозионного гидротехнического сооружения, включающего создание водоперераспределяющей траншеи, ориентированной по горизонталям местности, с водоудерживающим земляным валом и водоудерживающим экраном, траншея заполняется наполнителем. При этом водоудерживающий экран выполнен путем покрытия материалом геокомпозитным дренажным с геомембраной стенки траншеи, примыкающей к водоудерживающему земляному валу, вместе с валом, а противоположную стенку и дно траншеи покрывают материалом геокомпозитным дренажным. В качестве заполнителя используют водопроводящий природный наполнитель в виде керамзитового гравия фракцией 20-40 мм. Благодаря предложенному конструктивному решению, увеличиваются надежность и стабильность функционирования противоэрозионного сооружения и, как следствие, повышается эффективность борьбы с водной эрозией на пахотных склоновых землях.

Ключевые слова: водная эрозия, противоэрозионные гидротехнические сооружения, эрозионные процессы, способы защиты склонов, поверхностные стоки.

Цитирование. Слабунова А. В., Слабунов В. В. Способ защиты склонов от водной эрозии. Известия НВ АУК. 2021. 3(63). 388-396. DOI: 10.32786/2071-9485-2021-03-40.

Авторский вклад. Все авторы настоящего исследования принимали непосредственное участие в планировании, выполнении или анализе данного исследования. Все авторы настоящей статьи ознакомились и одобрили представленный окончательный вариант.

Конфликт интересов. Авторы заявляют об отсутствии конфликта интересов.

Введение. Ростовская область - регион широкого и повсеместного распространения водной эрозии. Причина развития эрозионных процессов - высокая степень сельскохозяйственной освоенности земель в совокупности с природно-ландшафтными условиями области [7]. Так, земли сельскохозяйственного назначения составляют значительную часть территории области $-87,8$ \% - от ее общей площади, из них 92,6 \% 
составляют сельскохозяйственные угодья, около 40 \% из которых, согласно карте эрозионного районирования Ростовской области, подвержены водной эрозии (Экологический вестник Дона, 2020). В связи с этим, земледелие в рассматриваемом регионе должно носить ярко выраженный почвозащитный характер [3, 4, 6, 8, 11$]$.

Защита сельскохозяйственных угодий от процессов эрозии является государственной задачей, решаемой программно-целевым методом. В ведомственной программе «Развитие мелиоративного комплекса России» Государственной программы развития сельского хозяйства и регулирования рынков сельскохозяйственной продукции, сырья и продовольствия предусмотрена защита земель от водной эрозии в размере 724,37 тыс. га до 2025 г. (Постановление Правительства РФ от 14 июля 2012 г. № 717).

В настоящее время для защиты почвы от эрозии используются различные технологии и пути решения проблемы, однако они требуют постоянного совершенствования, что, в свою очередь, вызывает необходимость разработки новых способов и методов, полученных на основании непрекращающихся научных исследований как в России, так и за рубежом $[5,9,10,12-14]$, а также более доступных в финансовом плане сельхозтоваропроизводителям.

Одним из широко применяемых противоэрозионных мероприятий (особенно в комплексе с лесомелиоративными и агротехническими) на овражно-балочных и пахотных склоновых землях является устройство инженерных гидротехнических сооружений, которые имеют довольно высокую эффективность в борьбе с водной эрозией [1, 2]. В основе разработки противоэрозионных комплексов лежит регулирование стока (путем перехвата, задержания и перераспределения) временных водных потоков (сток дождевых и талых вод) [9].

Целью исследования является разработка усовершенствованных конструктивных решений противоэрозионных гидротехнических сооружений для защиты склонов от водной эрозии.

Материалы и методы. Информационную основу исследования составили: исследования различных авторов, посвященные проблеме водной эрозии, материалы патентного поиска известных конструктивных решений, способствующих защите склонов от водной эрозии. Сравнительный анализ конструктивных решений проводился с помощью общенаучных (анализ и синтез) методов.

Результаты и обсуждение. Главное назначение противоэрозионных гидротехнических сооружений - это прекращение роста оврагов, отвод водного потока с водосборной площади, пропуск расчетного расхода воды и гашение избытка энергии потока, предотвращение заиления водных объектов. В связи с этим, они подразделяются на четыре вида. На рисунке 1 представлена классификация противоэрозионных гидротехнических сооружений в зависимости от назначения и конструкции.

\section{ПРОТИВОЭРОЗИОННЫЕ ГИДРОТЕХНИЧЕСКИЕ СООРУЖЕНИЯ} ANTI-EROSION HYDRAULIC STRUCTURES

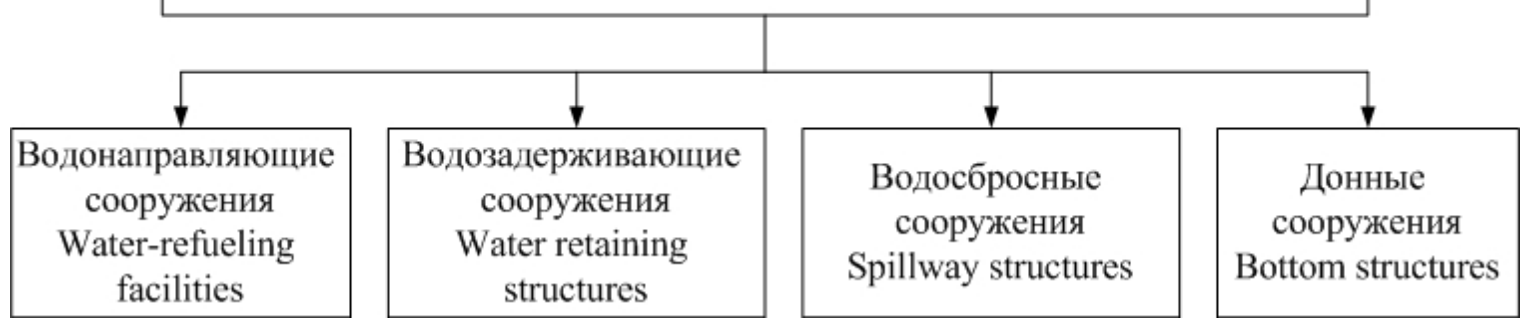

Рисунок 1 - Классификация противоэрозионных гидротехнических сооружений

Figure 1 - Classification of anti-erosion hydraulic structures 


\section{****** НЗВЕСТИЯ ***** \\ НИЖНЕВОАЖСКОГО АГРОУНИВЕРСИТЕТСКОГО КОМПАЕКСА: \\ НАУКА И ВЫСШЕЕ ПРОФЕССИОНААЬНОЕ ОБРАЗОВАНИЕ}

В качестве объекта исследований авторами выбран такой вид противоэрозионных сооружений, как водозадерживающие сооружения, в качестве которых выступают валы, траншеи, террасы, плотины-перемычки и т. д., обеспечивающие регулирование стока.

Анализ конструктивных решений показал существование различных способов защиты склонов от эрозии, основанных преимущественно на создании водозадерживающей траншеи.

Например, существующий способ (А. с. 1653553 СССР «Способ защиты склонов от эрозии») защиты склонов от эрозионных процессов описывает устройство траншеи с валом, которая, в свою очередь, наполняется неорганическим водопоглощающим материалом. Далее диагонально к склону производится укладка водоотводящих элементов (перфорированных труб) через расчетное расстояние, а в верхней части склона осуществляется посадка древесных растений. К отрицательным моментам использования данного способа можно отнести как стоимостные показатели, выражающиеся в высокой стоимости используемых материалов, так и технические и технологические - высокую трудоемкость выполнения работ и низкую пропускную способность водного потока в весеннее время вследствие влияния низких температур на используемый неорганический материал.

Способ защиты почв от водной эрозии (Патент РФ № 2644569 «Способ защиты почв от водной эрозии») включает создание водозадерживающей траншеи, заполненной неорганическим наполнителем, соединенной дренажной системой с водонакапливающим бассейном. Выявлены такие недостатки, как низкая эффективность и временность действия водозадерживающей траншеи из-за отсутствия укрепления стенок, а также высокая трудоемкость.

Отметим еще один способ защиты склонов (Патент РФ № 2467543 «Способ защиты склонов от водной эрозии»), который реализуется с помощью устройства дугообразных траншей с укладкой водонепроницаемого экрана. Траншея заполняется неорганическим материалом, позволяющим свободно фильтровать поступающий поверхностный сток в нижнюю часть траншеи для дальнейшего перераспределения вниз по профилю. Для удержания поверхностного стока в нижней части траншеи относительно склона устраивается водоудерживающий вал. Недостатками способа являются низкая эффективность и кратковременность функционирования траншеи из-за разрушения стоком верхней бровки откоса траншеи и снижения водопропускной способности неорганического фильтрующего наполнителя вследствие его кольматации.

Таким образом, анализ недостатков рассмотренных способов борьбы с водной эрозией выявил необходимость повышения надежности и стабильности функционирования водоперераспределяющей траншеи, заполненной органическим наполнителем, что будет способствовать росту эффективности борьбы с водной эрозией.

Авторами предлагается способ предотвращения водной эрозии с помощью противоэрозионного сооружения, работающего по принципу перераспределения поверхностного стока в нижележащие слои почвенного профиля.

Способ защиты склонов от водной эрозии включает в себя создание водоперераспределяющей траншеи, ориентированной по горизонталям местности, с водоудерживающим земляным валом и водоудерживающим экраном. Траншея заполнена водопроводящим природным наполнителем. Стенка траншеи, примыкающая к водоудерживающему земляному валу (нижняя стенка), вместе с валом покрыта материалом геокомпозитным дренажным с геомембраной, а противоположная стенка (верхняя стенка) и дно траншеи покрыты материалом геокомпозитным дренажным. 
Материал геокомпозитный дренажный с геомембраной совмещает функции дренирования и гидроизоляции, обеспечивая высокую водопроницаемость в плоскости полотна, а также нормально к этой плоскости, но только с одной стороны (по направлению из траншеи), позволяет обеспечить задержание поверхностного стока и перенаправление его в нижнюю часть траншеи и далее под действием гравитационных сил в глубину почвенного профиля, а также предотвратить размывание водоудерживающего земляного вала. Материал геокомпозитный дренажный выполняет функцию дренирования, обеспечивая высокую водопроницаемость во всех направлениях плоскости полотна, и предотвращает разрушение верхней стенки траншеи и кольматацию водопроводящего наполнителя траншеи. Полотна скреплены между собой термическим способом, к грунту крепятся анкерами.

Использование в качестве водопроводящего природного наполнителя керамзитового гравия фракцией 20-40 мм (который является экологически чистым материалом, недорог, обладает высокой водо- и морозостойкостью, не гниет и не разлагается) обеспечивает повышенную пропускную способность для воды и, как следствие, стабильное перераспределение воды в нижележащие слои почвенного профиля. Засыпается вровень с поверхностью земли.

Размеры траншеи зависят от величины планируемого задержания стока. Гидрологические расчеты ведутся с учетом задержания стока $10 \%$ обеспеченности (максимальный сток раз в 10 лет).

«Технологический цикл» работы предлагаемого способа можно описать следующим образом. Так, в весеннее время (период снеготаяния) и (или) во время выпадения естественных осадков (ливневых дождей) вода, проникая вглубь почвы, задерживается водоперераспределяющей траншеей за счет устройства в ней стенки, покрытой материалом геокомпозитным дренажным (верхняя стенка), обеспечивающим перераспределение под действием гравитационных сил воды в глубину почвенного профиля. В свою очередь, поверхностный сток улавливается водоудерживающим земляным валом, покрытым материалом геокомпозитным дренажным с геомембраной (нижняя стенка), обеспечивающей перераспределение поступающей воды в водоперераспределяющую траншею, где, проходя через слой водопроводящего природного наполнителя, направляется на дно траншеи и далее в нижележащие слои почвенного профиля.

В результате перехвата и перенаправления поверхностного стока в нижележащие слои почвенного профиля водоперераспределяющей траншеей предотвращается смыв почвы, снижаются эрозионные процессы. Кроме того, прохождение воды через слой керамзитового гравия, который не промерзает и не деформируется, способствует ее очищению от взвешенных веществ, что благоприятно сказывается на ее качестве. При этом покрытие стенки траншеи материалом геокомпозитным дренажным (верхняя стенка) предотвращает ее разрушение и, как следствие, кольматацию органического наполнителя, что способствует недопущению снижения водопропускной способности траншеи в целом, а покрытие противоположной стенки траншеи (нижняя стенка) и вала материалом геокомпозитным дренажным с геомембраной обеспечивает задержание стока и перенаправление его в нижележащие слои, предотвращая размыв сооружения. В совокупности повышаются стабильность и надежность функционирования водоперераспределяющей траншеи, увеличивается срок службы.

Для защиты склонов от водной эрозии предлагается конструктивное решение противоэрозионного гидротехнического сооружения, схема которого приведена на рисунке 2 . 


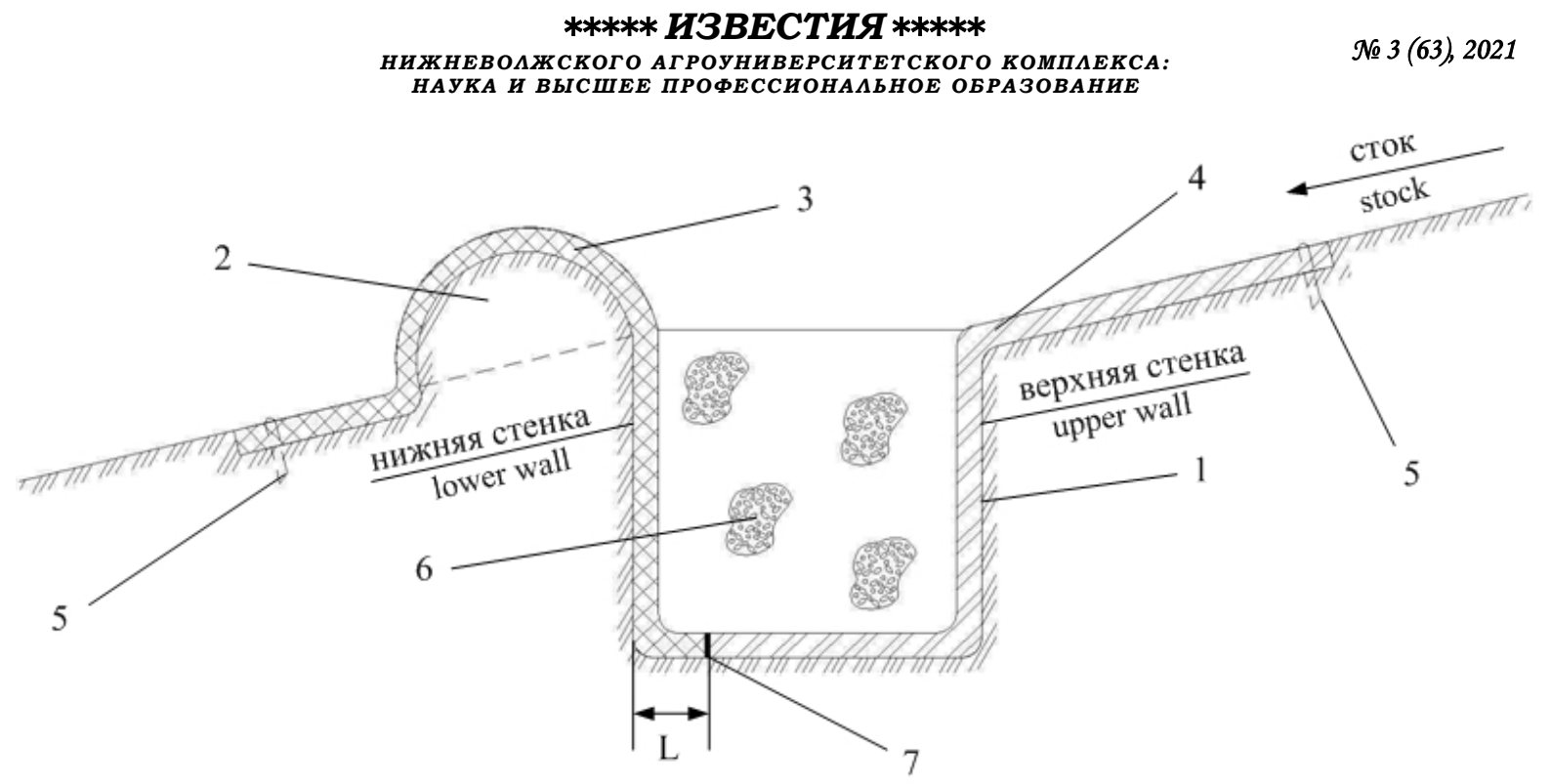

Рисунок 2 - Схема противоэрозионного гидротехнического сооружения:

1 - водоперераспределяющая траншея; 2 - водоудерживающий земляной вал;

3 - материал геокомпозитный дренажный с геомембраной; 4 - материал

геокомпозитный дренажный; 5 - анкеры; 6 - водопроводящий природный наполнитель; 7 - место монтажа геокомпозитных материалов; L - расстояние, определяемое минимальным технологическим расстоянием сварки материала

Figure 2 - Diagram of an anti-erosion hydraulic structure:

1 - water-distributing trench; 2 - water-retaining earthen rampart;

3 -geocomposite drainage material with geomembrane; 4 - geocomposite drainage material; 5-anchors; 6 - natural water supply filler; 7-installation site of geocomposite materials; $\mathrm{L}$ - distance determined by the minimum technological distance of welding of the material

Таким образом, разработанный способ защиты склонов от водной эрозии включает создание на склоне через определенное расстояние водоперераспределяющей траншеи 1, ориентированной по горизонтали местности, которую разрабатывают с перемещением грунта в водоудерживающий земляной вал 2 с последующей прикаткой (уплотнением грунта). Далее на стенку траншеи, которая примыкает к водоудерживающему земляному валу 2, и на сам вал укладывают материал геокомпозитный дренажный с геомембраной 3 (ГОСТ 33068 «Материалы геосинтетические для дренажных систем. Общие технические требования»), а на противоположную стенку и дно водоперераспределяющей траншеи 1 укладывают материал геокомпозитный дренажный 4. Полотна скрепляют между собой термическим способом в месте монтажа геокомпозитных материалов 7 на расстоянии $L$, которое определяется минимальным технологическим расстоянием сварки материала. К грунту крепят анкерами 5. Заполняют траншею 1 вровень с поверхностью земли водопроводящим природным наполнителем 6 , представляющим собой керамзитовый гравий фракцией 20-40 мм (ГОСТ 32496 Заполнители пористые для легких бетонов. Технические условия).

Способ защиты склонов от водной эрозии работает следующим образом. Поверхностный сток, стекая по склону, задерживается водоудерживающим земляным валом 2 и стенкой траншеи, покрытой материалом геокомпозитным дренажным с геомембраной 3 (нижняя стенка), поступает в водоперераспределяющую траншею 1 , заполненную водопроводящим природным наполнителем 6 в виде керамзитового гравия, который проводит воду в нижнюю часть траншеи, а далее под действием гравитационных сил в ниже- 
лежащие слои почвенного профиля. При этом водопроводящая способность наполнителя сохраняется и в ранневесеннее время (период таяния снега). Покрытие противоположной стенки и дна траншеи материалом геокомпозитным дренажным 4 (верхняя стенка) позволяет предотвратить разрушение кромки и стенки траншеи и, как следствие, кольматацию водопроводящего органического наполнителя 6 , что способствует сохранению его водопропускной способности на долгое время, а в совокупности - повышению стабильности и надежности функционирования противоэрозионного сооружения. В свою очередь, используемый слой керамзитового гравия выполняет функцию фильтра, так как фильтрация поверхностного стока через него позволяет очистить от находящихся в воде взвешенных частиц. Данный эффект снижает экологическую нагрузку от перераспределяемого поверхностного стока в водоприемник (водный объект).

Выводы. В результате исследований авторами предложено конструктивное решение противоэрозионного гидротехнического сооружения, включающего создание водоперераспределяющей траншеи, ориентированной по горизонтали местности, с водоудерживающим земляным валом и водоудерживающим экраном, траншея заполняется наполнителем. При этом водоудерживающий экран выполнен путем покрытия материалом геокомпозитным дренажным с геомембраной стенки траншеи, примыкающей к водоудерживающему земляному валу, вместе с валом, а противоположную стенку и дно траншеи покрывают материалом геокомпозитным дренажным. При этом в качестве заполнителя используют водопроводящий природный наполнитель в виде керамзитового гравия фракцией 20-40 мм. Благодаря предложенному конструктивному решению, увеличиваются надежность и стабильность функционирования противоэрозионного сооружения.

\section{Библиографический список}

1. Гогичаишвили Г. П. Эрозия почв в речных бассейнах Грузии // Почвоведение. 2016. № 6. С. 745-754.

2. Карта агрогенной эродированности почв России / А. Л. Иванов [и др.] // Доклады российской академии наук. Науки о земле. 2020. Т. 493. № 2. С. 99-102.

3. Мальцева К. А., Ермолаев О. П. Потенциальные эрозионные потери почвы на пахотных землях европейской части России // Почвоведение. 2019. № 12. С. 1502-1512.

4. Отечественные подходы к оценке степени деградации почв и земель / Э. Н. Молчанов [и др.] // Почвоведение. 2015. № 11. С. 1394.

5. Савельева Д. А., Каличкин В. К. Применение цифровых технологий при изучении водной эрозии почв Западной Сибири // Сибирский вестник сельскохозяйственной науки. 2019. T. 49. № 4. С. $86-100$.

6. Современное состояние гумусированности пахотных черноземов настоящих степей (на примере Ростовской области) / О. В. Чернова [и др.] // Юг России: экология, развитие. 2020. Т. 15. № 4 (57). С. 99-113.

7. Сухомлинова Н. Б., Суханова А. В. Оценка эффективности землепользования в агроландшафтах Ростовской области // Научный журнал Российского НИИ проблем мелиорации. 2017. № 4 (28). C. 263-275. http:www.rosniipm-sm.ru/article?n=344.

8. Сухомлинова Н. Б., Чешев А. С. Эколого-мелиоративные мероприятия в районах с развитой эрозией почв // Экономика и экология территориальных образований. 2019. Т. 3, № 1. C. 35-45.

9. Сухомлинова Н. Б. Особенности организации территории сельскохозяйственных угодий в современных условиях (на примере Ростовской области) // Международный научноисследовательский журнал. 2019. Вып. № 11(89). Ч. 2. С. 67-73.

10. Фетюхин И. В., Черненко В. В. Факторы развития, моделирование и прогнозирование эрозии почвы // Международный сельскохозяйственный журнал. 2018. № 1. С. 11-13.

11. Яковлева Е. П. Негативные свойства агроэкосистем юга европейской части России и стратегия мелиоративных мероприятий // Труды кубанского государственного аграрного университета. 2016. № 60. С. 345-349. 
12. Browning T. N., Sawyer D. E. Vulnerability to watershed erosion and coastal deposition in the tropics // Scientific Reports. 2021. Vol. 11. Iss. 1. 11 p.

13. Effects of vegetation and climate on the changes of soil erosion in the Loess Plateau of China / F. Jin, W. Yang, J. Fu, Z. Li // Science of the Total Environment. 2021. 773. 145514. 12 p.

14. How can stream bank erosion be predicted on small water courses? Verification of BANCS model on the Kubrica watershed / Z. Allmanova, M. Vlckova, M. Jankovsky, M. Allman, J. Merganic // International Journal of Sediment Research. 2021. № 36 (21). P. 419-429.

Conclusions. . As a result of the research, the authors proposed a constructive solution for an anti-erosion hydraulic structure, including the creation of a water-distributing trench, oriented horizontally, with a water-retaining earthen shaft and a water-retaining screen, the trench is filled with filler. In this case, the water-retaining screen is made by covering the wall of the trench adjacent to the water-retaining earthen shaft with a geocomposite drainage material with a geomembrane, together with the shaft, and the opposite wall and the bottom of the trench are covered with a geocomposite drainage material. At the same time, a waterconducting natural filler in the form of expanded clay gravel with a fraction of $20-40 \mathrm{~mm}$ is used as a filler. Thanks to the proposed design solution, the reliability and stability of the operation of the anti-erosion structure increases.

\section{References}

1. Gogichaishvili G. P. \}roziya pochv v rechnyh bassejnah Gruzii // Pochvovedenie. 2016. № 6. P. 745-754.

2. Karta agrogennoj jerodirovannosti pochv Rossii / A. L. Ivanov [i dr.] // Doklady rossijskoj akademii nauk. Nauki o zemle. 2020. T. 493. № 2. P. 99-102.

3. Mal'ceva K. A., Ermolaev O. P. Potencial'nye jerozionnye poteri pochvy na pahotnyh zemlyah evropejskoj chasti Rossii // Pochvovedenie. 2019. № 12. SP. 1502-1512.

4. Otechestvennye podhody k ocenke stepeni degradacii pochv i zemel' / Je. N. Molchanov [i dr.] // Pochvovedenie. 2015. № 11. P. 1394.

5. Savel'eva D. A., Kalichkin V. K. Primenenie cifrovyh tehnologij pri izuchenii vodnoj jerozii pochv Zapadnoj Sibiri // Sibirskij vestnik sel'skohozyajstvennoj nauki. 2019. T. 49. № 4. P. 86-100.

6. Sovremennoe sostoyanie gumusirovannosti pahotnyh chernozemov nastoyaschih stepej (na primere Rostovskoj oblasti) / O. V. Chernova [i dr.] // Yug Rossii: jekologiya, razvitie. 2020. T. 15. № 4 (57). P. 99-113.

7. Suhomlinova N. B., Suhanova A. V. Ocenka jeffektivnosti zemlepol'zovaniya v agrolandshaftah Rostovskoj oblasti // Nauchnyj zhurnal Rossijskogo NII problem melioracii. 2017. № 4 (28). P. 263-275. http:www.rosniipm-sm.ru/article? $n=344$.

8. Suhomlinova N. B., Cheshev A. S. Jekologo-meliorativnye meropriyatiya v rajonah s razvitoj ]roziej pochv // Jekonomika i jekologiya territorial'nyh obrazovanij. 2019. T. 3, № 1. P. 35-45.

9. Suhomlinova N. B. Osobennosti organizacii territorii sel'skohozyajstvennyh ugodij v sovremennyh usloviyah (na primere Rostovskoj oblasti) // Mezhdunarodnyj nauchno-issledovatel'skij zhurnal. 2019. Vol. № 11(89). Ch. 2. P. 67-73.

10. Fetyuhin I. V., Chernenko V. V. Faktory razvitiya, modelirovanie i prognozirovanie ]rozii pochvy // Mezhdunarodnyj sel'skohozyajstvennyj zhurnal. 2018. № 1. P. 11-13.

11. Yakovleva E. P. Negativnye svojstva agrojekosistem yuga evropejskoj chasti Rossii i strategiya meliorativnyh meropriyatij // Trudy kubanskogo gosudarstvennogo agrarnogo universiteta. 2016. № 60. P. 345-349.

12. Browning T. N., Sawyer D. E. Vulnerability to watershed erosion and coastal deposition in the tropics // Scientific Reports. 2021. Vol. 11. Iss. 1. 11 p.

13. Effects of vegetation and climate on the changes of soil erosion in the Loess Plateau of China / F. Jin, W. Yang, J. Fu, Z. Li // Science of the Total Environment. 2021. 773. 145514. 12 p.

14. How can stream bank erosion be predicted on small water courses? Verification of BANCS model on the Kubrica watershed / Z. Allmanova, M. Vlckova, M. Jankovsky, M. Allman, J. Merganic // International Journal of Sediment Research. 2021. № 36 (21). P. 419-429. 
Slabunova Alexandra Vasilievna, Senior Researcher FSBSE «Russian scientific research institute of land improvement problems» (Baklanovsky ave., 190, Novocherkassk, Rostov region, Russian Federation, 346421), Candidate of Technical Sciences, tel. 8 (928)-129-01-60, e-mail: SlabunovaAV@yandex.ru. ORCID: 0000-0001-6769-3866.

Slabunov Vladimir Viktorovich, Leading Research Scientist FSBSE «Russian scientific research institute of land improvement problems» (Baklanovsky ave., 190, Novocherkassk, Rostov region, Russian Federation, 346421), Candidate of Technical Sciences, tel. 8(989)-626-24-95, e-mail: Slabunovvv@mail.ru. ORCID: 0000-0003-0150-5193.

\title{
Информация об авторах
}

Слабунова Александра Васильевна, старший научный сотрудник Федерального государственного бюджетного научного учреждения «Российский научно-исследовательский институт проблем мелиорации», (346421, Российская Федерация, Ростовская область, г. Новочеркасск, пр. Баклановский, 190), кандидат технических наук, тел. 8(928)-129-01-60, e-mail: SlabunovaAV@yandex.ru. ORCID: 0000-0001-6769-3866.

Слабунов Владимир Викторович, ведущий научный сотрудник Федерального государственного бюджетного научного учреждения «Российский научно-исследовательский институт проблем мелиорации», (346421, Российская Федерация, Ростовская область, г. Новочеркасск, пр. Баклановский, 190), кандидат технических наук, тел. 8(989)-626-24-95, e-mail: Slabunovvv@mail.ru. ORCID: 00000003-0150-5193.

DOI: $10.32786 / 2071-9485-2021-03-41$

INCREASING THE SERVICE LIFE OF AGRICULTURAL MACHINE PARTS FROM IRON-CARBON ALLOYS BY THE THERMAL TREATMENT

\author{
A.V. Gribenchenko, A. I. Ryadnov \\ Volgograd State Agrarian University, Volgograd
}

Received 12.05.2021

Submitted 05.08.2021

\section{Summary}

The question of increasing the durability of agricultural machine parts by means of heat treatment is considered. The changes in the structure and, in this regard, the mechanical properties of the hardened and tempered steel can occur under the influence of various deviations in the heat treatment mode. At a hardness of HRC 25-30, granular structures obtained by quenching with high tempering (improvement) undoubtedly have advantages over plate structures, since steel with a sorbitol structure is more durable and ductile than steel of the same hardness, but with a plate perlite structure. If the maximum achievable hardness, when quenching steel with a carbon content of $0.2 \%$ is HRC 46, then with an increase in the carbon content to $0.6 \%$, the values of the highest hardness reach HRC 62-63. If you continue to increase the carbon content, then at concentrations exceeding $0.8 \%$, the hardness of the hardened steel increases slightly due to the appearance of residual austenite in the structure.

\begin{abstract}
Introduction. The results of research aimed at increasing the durability of machine parts due to the processes occurring during various types of heat treatment are presented. Currently, the available technologies for producing machine parts from carbon steels with specified mechanical properties have largely exhausted the possibilities for increasing the requirements for strength indicators imposed on the working bodies of modern machines. For this reason, the improvement of the quality indicators of steel machine parts by heat treatment is of great interest for studying the interfacial distribution of alloying and impurities, as well as their impact on the behavior of the main strengthening element-carbon. Materials and methods. To consider the nature of the phase transformations occurring during the heat treatment of ironcarbon alloys, samples of alloy steel grade $45 \mathrm{G}$ were studied. Changes in the structure were observed using a NEOPHOT-32 microscope, changes in the mechanical properties of hardened and tempered steel occurring under the influence of various deviations in the heat treatment mode were studied on hardness tester TK (Rockwell). Residual austenite in the structure of carbon or alloy steel reduces the hardness and
\end{abstract}

